\title{
conjugando tradições: o pensamento econômico do bispo azeredo coutinho entre a herança ibérica e as ideias ilustradas setecentistas (1791-1816) ${ }^{\star}$
}

\author{
Nelson Mendes Cantarino $\star \star$ \\ Doutor em História Social pela Universidade de São Paulo (USP).
}

\begin{abstract}
RESUMO
A trajetória de José Joaquim da Cunha Azeredo Coutinho (1742-1821) é bem conhecida da historiografia brasileira, Bispo de Olinda, membro do governo provisório da Capitania de Pernambuco, último inquisidor geral e deputado eleito pelo Rio de Janeiro para as Cortes de Lisboa. Intransigente defensor da ordem estabelecida, Azeredo Coutinho distinguiu-se, inicialmente, pela publicação de diversos textos econômicos impressos por ordem da Academia Real das Ciências de Lisboa. Mas qual seria a matriz teórica do pensamento econômico do bispo Azeredo Coutinho? Para responder a essa indagação, devemos identificar quais eram os propósitos que o prelado buscava alcançar com a publicação de seus ensaios, discursos e memórias. Como um vassalo fiel, o primeiro deles era aconselhar o monarca a criar um império fundado na justiça e na virtude. Para isso, nada melhor que a economia política, ou seja, a "ciência do governo e a esta ciência que se
\end{abstract}

\begin{abstract}
The trajectory of Joaquim José da Cunha Azeredo Coutinho (1742-1821) is well known to Brazilian historiography, he was Bishop of Olinda, a member of the provisional government of the province of Pernambuco, last inquisitor-general and deputy elected by the Rio de Janeiro to Lisbon Cortes.. Uncompromising defender of the established order, Azeredo Coutinho distinguished initially by the publication of several economic texts printed by order of the Royal Academy of Sciences. But what would be the theoretical matrix of economic thought of Bishop Azeredo Coutinho? To answer this question, we must identify what were the purposes that the archbishop sought to achieve with the publication of his essays, speeches and memoirs. As a faithful vassal, the first purpose was to advise the monarch to create an empire founded on justice and virtue. There is nothing better than political economy, ie, the "science of government
\end{abstract}

* Submetido: setembro de 2012; aceito dezembro, 2012.

$\star \star$ Pós-doutorando associado ao Instituto de Economia da Universidade Estadual de Campinas (IE/UNICAMP). Professor da Fundação Escola de Comércio Álvares Penteado (FECAP-SP) e do Instituto de Ensino e Pesquisa de São Paulo (INSPER-SP). Email: nelson.cantarino@fecap.br 
ocupa essencialmente da prosperidade do Estado, da fidelidade dos povos e dos verdadeiros meios de a procurar". Neste artigo busco reconstituir quais tradições do pensamento econômico o bispo luso-brasileiro utiliza em suas obras, sempre em conformidade com a ideia de um Império luso-brasileiro na qual as tensões entre Metrópole e Colônia devem ser apaziguadas.

Palavras-chave: Bispo Azeredo Coutinho. Reformismo ilustrado português, Pensamento econômico. and the science which deals essentially the prosperity of the state, the fidelity of the people and true means of the search." In this article I seek to reconstruct what traditions of economic thought Luso-Brazilian Bishop uses in his works, always in accordance with the idea of a Luso-Brazilian Empire in which the tensions between metropolis and colony must be appeased.

Key-words: Bishop Azeredo Coutinho. Reformism illustrated Portuguese, Economic thought.

Bispo de Olinda, membro do governo provisório da Capitania de Pernambuco, último inquisidor geral e deputado eleito pelo Rio de Janeiro para as Cortes de Lisboa. A trajetória de José Joaquim da Cunha Azeredo Coutinho (1742-1821) é bem conhecida da historiografia brasileira. Intransigente defensor da ordem estabelecida, Azeredo Coutinho distinguiu-se, inicialmente, pela publicação de diversos textos econômicos impressos por ordem da Academia Real das Ciências de Lisboa. Mas qual seria a matriz teórica do pensamento econômico do bispo Azeredo Coutinho? Para responder a essa indagação devemos identificar quais eram os propósitos que o prelado buscava alcançar com a publicação de seus ensaios, discursos e memórias. Como um vassalo fiel, o primeiro deles era aconselhar o monarca a criar um império fundado na justiça e na virtude. Para isso, nada melhor que a economia política, ou seja, a "ciência do governo e a esta ciência que se ocupa essencialmente da prosperidade do Estado, da fidelidade dos povos e dos verdadeiros meios de a procurar" (HOLANDA, Apud COUTINHO, 1966, p. 189) ${ }^{1}$.

Em um contexto de crescente disputa internacional e crítica ao ordenamento social do Antigo Regime um governo justo e virtuoso seria capaz de prosperar, trazendo harmonia entre os diversos corpos do Estado. O segundo objetivo de Azeredo era estabelecer a inserção internacional do Império Português em bases mais sólidas. Ao contrário de alguns de seus contemporâneos, em momento algum ele contesta a ideia de

1 Tal definição encontra-se na dedicatória do Discurso sobre o estado atual das minas do Brasil. (COUTINHO, 1966: 189). 
colonização, suas vantagens ou o direito de colonizar ${ }^{2}$. No fundo, seus objetivos ainda são os mesmos que guiaram os reformadores portugueses da primeira metade do século XVIII, ou seja, a consolidação do tripé estratégico: prosperidade econômica, força militar e liderança política.

Mais propriamente no que diz respeito à justiça e à virtude, preceitos vulgares na literatura econômica do período, justiça seria o princípio moral em nome do qual o direito deve ser respeitado; já a virtude seria aquela devoção ao bem público, que deveria ser sempre procurada com eficácia, mérito e propriedade (POCOCK, 2003: 83-99). Uma ideia-chave permeia toda a obra de Azeredo Coutinho: a prosperidade econômica apazigua conflitos entre ordens e bloqueia a influência da "seita dos filósofos" que, para seu horror, cismava em "civilizar a África, reformar a Europa, corrigir a Ásia e regenerar a América"3.

Nesse sentido, a prosperidade de Portugal é indissociável do destino de suas colônias. Assim como D. Luís da Cunha (1662-1749), Azeredo

2 Antes mesmo de Adam Smith publicar sua obra-prima em 1776 outros autores já haviam problematizado o papel das colônias no desenvolvimento dos países europeus. O regime de exclusivo já havia sido contestado por François Quesnay em seu Tableau Économique (1758). A exploração das colônias também é alvo de severas críticas na Histoire Philosophique et Politique des établissements et du commerce des Européens dans les deux Indes. (4 vols, 1770) do abade Guillaume de Raynal.Josiah Tucker já criticava o tratamento que a Coroa britânica dispensava a suas colônias da América do Norte em seus trabalhos Considerations upon American colonies (1770) e The true interest of Great Britain set forth with regard to colonies (1774). (PEDREIRA, apud COUTINHO, 1992: XI-XII).

3 Uma passagem bem esclarecedora está na dedicatória da $2^{\mathrm{a}}$ edição do Ensaio Econômico de Azeredo Coutinho:"(...) quanto seria diferente o destino de um Império fundado na justiça, e na virtude! A agricultura, as artes, as ciências, o comércio, animados à sombra da paz, apartariam do meio dele a ociosidade, a ignorância e a miséria. O soberano do Estado protegeria as diferentes ordens, e seria adorado. Ele teria conhecido que alguns dos membros da sociedade não poderia perder, sem que também perdesse o corpo inteiro; e que era necessário ocupar-se da felicidade de todos. A imparcial eqüidade presidiria à observância dos Tratados que ela tivesse ditado; à estabilidade das Leis que ela teria simplificado; à repartição dos impostos que ela tivesse proporcionado aos encargos público: tudo seria equilibrado. Todas as potências que tivessem relações com um tal Império, como interessadas na conservação dele, ao menor perigo que o ameaçasse, se armariam em sua defesa; mas, ainda na falta de socorros estrangeiros, ele por si só poderia opor ao agressor injusto a barreira impenetrável de um povo rico e numeroso, para o qual a palavra Pátria não seria um nome vão: quanto um Império mais se aproximar deste ponto central da justiça e da virtude, tanto ele será mais firme e mais amado: quanto mais se afastar dele, tanto será mais cruel, mais tirano, e menos seguro." (COUTINHO, 1966: 60). 
acreditava que as riquezas coloniais mantinham o Reino fortalecido em uma conjuntura de concorrência estatal, em que a riqueza ainda era medida por parâmetros mercantis ${ }^{4}$.

Entre escritos de maior fôlego e outros de ocasião aquele que melhor expõe o projeto estratégico de Azeredo Coutinho para o Império é o Ensaio econômico sobre o comércio de Portugal e suas colônias. Tal obra foi editada, pelo menos, três vezes em um espaço de trinta e quatro anos. Sua primeira edição (1794) foi dedicada ao então príncipe D. João, elevado à regência dois anos antes devido ao ensandecimento de sua mãe. Naquela oportunidade, o jovem regente lidava com os efeitos do aprofundamento da Revolução Francesa na esfera internacional e com o "perigo" do contágio do ideário crítico da ilustração nas paragens do mundo português. A segunda edição, publicada em 1816, foi dedicada ao então Príncipe da Beira e futuro Imperador do Brasil, D. Pedro de Alcântara. Era a circunstância na qual a Santa Aliança conseguiu impor seu concerto de nações após o Congresso de Viena (1815), uma excelente ocasião para fundar novamente um império com as características políticas e sociais do Antigo Regime. A terceira edição é de 1828, momento no qual Portugal deve repensar seu futuro após o reconhecimento da independência do Brasil ${ }^{5}$.

O Ensaio Econômico trás alguns conceitos e argumentos mercantis, além de outros tipos de argumentos associados, por alguns autores, ao ideário liberal típico da Ilustração.Assim, para Fernando Novais,Azeredo Coutinho sofria com o grande dilema do reformismo ilustrado português: a dificil manutenção do ponto de equilíbrio entre a assimilação do pensamento crítico das Luzes e a contenção de seus efeitos contestatórios no Absolutismo e no Sistema Colonial. O raciocínio do bispo fluminense é um exemplo consumado de mercantilismo ilustrado: incapaz de pensar a economia

4 Segundo Azeredo, “(...) tudo quanto uma nação ganha de uma parte, diminui a potência real ou relativa das suas rivais; e, reciprocamente, se aumenta tudo quanto elas perdem." (COUTINHO, 1966: 81).

5 As três edições em questão foram publicadas pela Tipografia da Academia Real das Ciências de Lisboa. A segunda é revista pelo autor. Suas revisões ficaram, basicamente, na inclusão de notas explicativas de caráter histórico. Também são numerosas as notas com relatos e conclusões alusivas a sua experiência como membro do governo provisório da Capitania de Pernambuco. A terceira edição é, na verdade, uma reimpressão da segunda, sem maiores alterações. Por sua abrangência, a edição de 1816 é a mais utilizada pelos estudiosos e será nossa principal referência. 
do Império Português fora de um mercantilismo bafejado pela Ilustração. Nesse sentido, a visão mercantilista da colonização mantém-se na base de suas reflexões econômicas (NOVAIS, 1979:230 - 231).

Essa dualidade conceitual é um bom ponto de partida para entendermos alguns dos preceitos centrais do texto do Ensaio como, por exemplo, a noção de comércio e as formas como este deveria ser incentivado e compreendido pela Coroa. Ainda como D. Luís da Cunha, Azeredo entendia que, para Portugal estabelecer-se como potência de primeira grandeza, era necessário ter o controle efetivo das riquezas do Império. Era necessário, então, transformar as conquistas, as possessões e os domínios do ultramar em colônias de fato, ou seja, territórios dependentes e ao serviço exclusivo da Metrópole. $\mathrm{O}$ controle mais racional dos recursos da América Portuguesa levaria a Coroa ao seu lugar: entre as principais potências europeias ${ }^{6}$.

Uma dessas releituras está, justamente, em seu conceito de comércio. O objetivo deste seria aumentar a comodidade dos homens, tornando os bens supérfluos úteis, e os bens úteis necessários. Para isso, seria primordial que a economia não ficasse no nível da subsistência, diversificando sua agricultura e sua indústria. Assim, seria possível estimular o comércio de navegação, recurso que colocaria as riquezas nacionais em movimento e faria com que os agentes privados fossem capazes de acumular riqueza tanto para si como para o Estado (ALDEMAN, 2006: 150-151).

Nesse ponto de vista, o comércio não é um fim, mas um meio de os agentes privados tornarem-se mais prósperos.Além disso, ao tratar do tema, Azeredo aproxima-se do autor com o qual mais dialoga: Charles-Louis de Secondat, Barão de La Brède e de Montesquieu (1689-1755) ${ }^{7}$.

Nesse momento da discussão, faz-se necessário esclarecer um ponto. Em uma passagem antológica Sérgio Buarque de Holanda flagra Aze-

6 Antonio Manuel Hespanha, em artigo acerca do "caráter português" da expansão ultramarina, defende a opinião de François-Xavier Guerra. Para este, a palavra colônia, com o sentido de unidade vinculada, não ao Rei, mas à Metrópole, aparece em espanhol apenas na segunda metade do século XVIII, a partir de traduções de autores econômicos ingleses e franceses. Como veremos adiante, Azeredo possuía vários livros de autores ingleses e franceses em edições em francês (HESPANHA apud BICALHO, 2009: 51).

7 Não apenas no uso de ideias e conceitos, mas também com debate crítico, Azeredo foi um adversário ferrenho da noção de inferioridade intrínseca do homem dos trópicos, tese polêmica defendida por Montesquieu. 
redo pilhando trechos inteiros das Institutions Politiques, do Barão de Bielfeld (HOLANDA apud COUTINHO, 1966: 44-47). A partir disso, muitos passaram a defender a influência marcante de Bielfeld e do Cameralismo germânico na obra do prelado fluminense ${ }^{8}$.

Ressaltamos que Azeredo cita Bielfeld pontualmente e em raras ocasiões. A principal delas para mostrar que uma marinha própria é fundamental para a independência econômica e política dos Estados. A maior parte das citações relacionadas às Institutions Politiques está direcionada para esse tema: qual tipo de madeiras deve ser utilizado em navios; a discussão a respeito de a marinha mercante nacional ter uma correspondente de guerra; e a necessidade da criação de um corpo de marinheiros nacional' .

Quando chegamos à interpretação da "análise econômica" de Azeredo, a presença de Montesquieu é marcante. Assim, a noção de riqueza presente no Ensaio, por exemplo, é muito próxima daquela apresentada no Do Espírito das Leis. Segundo o prelado fluminense:

As riquezas dos Estados consistem ou em fundos de terras, ou em efeitos móveis; os fundos de terras, por isso que pedem mais a assistência e a vista de seus donos, são ordinariamente possuídos pelos habitantes de cada país, e constituem propriamente a riqueza de cada Estado em particular. Os efeitos móveis, como são dinheiro, bilhetes letras de câmbio, ações sobre as companhias, navios e todas as mercadorias, por isso que são universais e giram por toda a parte, pertencem ao mundo inteiro, que a este respeito compõe um só todo, de que todas as outras sociedades ou Estados são membros. O povo que relativamente possui mais destes efei-

8 Para uma melhor compreensão das práticas cameralistas, cf. TRIBE (2007: 8-31). A influência dessas práticas no reformismo ilustrado português foi estudada em CUNHA (2010: 36-47).

9 É a partir da necessidade de criar um corpo de marinheiros nacional que Azeredo viu uma oportunidade para inserção dos indígenas na sociedade portuguesa. Para ele, os indígenas possuíam as mesmas características intelectuais dos europeus e até poderiam ser considerados mais aptos em algumas atividades, como as pescarias, por exemplo. Aquelas comunidades que habitavam próximas de grandes rios ou do oceano forneceriam homens aptos para o serviço naval. Cf. COUTINHO, José Joaquim da Cunha de Azeredo. Ensaio econômico sobre o comércio de Portugal e suas colônias. In Obras econômicas de J. J. da Cunha de Azeredo Coutinho (1794-1804). Apresentação de Sérgio Buarque de Holanda. São Paulo: Companhia Editora Nacional, 1966: 92-116. 
tos móveis do universo, é o mais rico; porque entra proporcionalmente com um maior fundo, ou (expliquemo-nos assim) com um maior número de ações na grande companhia do comércio universal. (COUTINHO 1966: 84).

Na visão do magistrado francês, por sua vez:

As riquezas consistem em fundos territoriais ou em bens mobiliários: os fundos territoriais de cada país são geralmente possuídos por seus habitantes.A maioria dos Estados tem leis que desinteressam os estrangeiros pela aquisição de suas terras, só mesmo a presença do proprietário as faz valer: este gênero de riquezas pertence, pois, a cada Estado em particular. Mas os bens mobiliários, como o dinheiro, as cédulas, as letras de câmbio, as ações de companhias, navios, todas as mercadorias, pertencem ao mundo inteiro, que, nesta relação, forma apenas um único Estado, do qual todas as sociedades formam membros; o povo que possui a maioria desses bens mobiliários do universo é o mais rico; alguns Estados possuem-nos em grande quantidade; adquiriram-nos, cada um, por seus gêneros, pelo trabalho de seus operários, pela sua indústria, pelas suas descobertas e pelo próprio acaso. (MONTESQUIEU, 2000: 23).

A definição de Montesquieu é mais sofisticada, pois cita a importância do trabalho e do produto das manufaturas na geração de riquezas. Azeredo irá considerar tais itens em duas passagens de seu Discurso sobre o Estado Atual das Minas do Brasil (1804) ${ }^{10}$, talvez já influenciado por Adam Smith, citado no texto da edição francesa com tradução de J. A.

10 Na primeira das passagens, Azeredo escreve: "O agricultor, o fabricante, o artífice instruído pode aumentar a sua riqueza, acomodando e apropriando o seu terreno para este ou aquele gênero de cultura, ou dando um maior movimento ao seu braço, ou aumentando sua força por meio de alguma máquina; não é assim a respeito do mineiro: a maior extração do ouro não depende do seu braço; depende do acaso, e, muitas vezes, o que menos trabalha é o que descobre um tesouro mais rico.” $\mathrm{Na}$ segunda passagem, encontramos uma crítica à dependência portuguesa da mineração aurífera, com argumentos que podemos tirar de Montesquieu, dos fisiocratas e, até mesmo, de Smith: "O ouro por si só não é uma riqueza, é uma representação da riqueza. Todo o comércio das gentes consiste na permutação ou na troca de umas coisas pelas outras; as produções da natureza, o trabalho, a indústria e tudo aquilo que pode caber na fruição dos homens, são os que formam o objeto do comércio e da riqueza." (COUTINHO, 1966: 196, 204). 
Roucher ${ }^{11}$. Mas, ao confrontar Azeredo e Montesquieu, percebemos mais aproximações do que divergências. Nesse sentido, ambos possuem uma ideia similar acerca do mercado, seja como uma "grande companhia de comércio universal" ou como um "único Estado", passível de ser compreendido a partir das mesmas regras que validam as relações econômicas dentro de cada Reino soberano.

Dessa mesma forma, ambos os autores afastam-se de uma noção de riqueza bullionista, voltada para a acumulação de metais preciosos, seja a partir da exploração de minas próprias ou da política sistemática de superávits na balança comercial ${ }^{12}$. O produto da terra - a agricultura - e as manufaturas são a fonte dos produtos comercializáveis. Existe, então, uma distinção entre moeda e riqueza $a^{13}$.

A definição de Azeredo Coutinho para as noções de moeda e de dinheiro também se baseia, a priori, em Montesquieu e na tradução francesa de Smith ${ }^{14}$. Os dois itens em questão são representativos do valor de todos os produtos que entram no comércio ${ }^{15}$. Os metais preciosos

11 Recherches sur la nature et les causes de la richesse des nations. Traduit de l'Anglois de M. Smith, sur la quatrième Édition. Par M. Roucher; et suivies d'un volume de notes, par M. le Marquis de Condorcet, de l'Académie Françoise, et Secrétaire perpétuel de l'Académie des Sciences. À Paris, Chez Buisson, Libraire, rue Huate - Feuille, Hôtel de Coëtlosquet, n. ${ }^{\circ} 20.1790$.

12 Para a fascinação que os tesouros americanos exerceram sobre alguns autores mercantilistas (DEYON, 2009: 17-21).

13 Essa distinção é uma das inovações dos contemporâneos de Azeredo na Academia das Ciências de Lisboa (CARDOSO, 1989: 73).

14 Mais uma vez, a definição de Montesquieu serviu como referência para a de Azeredo: "A moeda é o signo que representa o valor de todas as mercadorias. Usa-se qualquer metal para que o símbolo seja durável, se desgaste pouco com o uso e, sem destruir, seja capaz de muitas divisões (...). Como o dinheiro é símbolo do valor das mercadorias, o papel é o símbolo do valor do dinheiro; e quando é bom, representa-o de tal modo que, quanto ao efeito, não há diferença”. Além disso, encontramos a ideia de que os metais preciosos são apenas sinais de riqueza, e não produtos de primeira necessidade: "O ouro e a prata são uma riqueza de ficção ou de um símbolo. Esses símbolos são muito duráveis e se destroem pouco, como convém a sua natureza. Quanto mais se multiplicam, mais perdem seu preço, porque representam menos coisas" (Montesquieu, 2000: 70, 62).

15 "O dinheiro é um sinal representativo de todas as coisas que entram no comércio das gentes; suponha-se que todas as mercadorias do mundo estão de uma parte, e que todo o dinheiro que há no mundo está da outra: todo o montão de dinheiro representará todo o montão de mercadorias, e, se do montão de dinheiro se tirar alguma parte, o resto desse montão de dinheiro representará sempre do mesmo modo todo o outro montão das mercadorias; logo, da mesma sorte, em qualquer 
são tomados, então, como sinais representativos dos preços das mercadorias $^{16}$. A abundância dos metais preciosos em uma determinada economia levaria à distorção dos preços, atrapalhando os cálculos do comércio. Utilizando um anacronismo, o raciocínio de Azeredo é correto ao analisar um dos aspectos do fenômeno inflacionário: excesso de moeda pode provocar um aumento generalizado no nível dos preços dos bens e serviços durante um período de tempo. Quando o nível geral dos preços aumenta, cada unidade da moeda perde seu poder de compra; assim a inflação é também um declínio no seu valor real ${ }^{17}$.

Esse racíocinio é explícito em sua Carta dirigida aos redatores do Investigador Português sobre o aumento do valor da moeda (COUTINHO, 1819: 63-66), uma crítica ao aumento artificial do valor da moeda corrente. Como destacou Moses Amzalak, o prelado criticou a medida porque o valor das mercadorias subiria com o da moeda, dificultando os cálculos comerciais; se as moedas de ouro existiam em abundância a solução era diminuir a mineração e investir mais na agricultura (Ibidem: 64).

Para Azeredo, no entanto, os preços não estão baseados no trabalho e, muito menos, no tempo necessário para a produção das mercadorias. Tal pensamento o afasta de Smith e o aproxima, ainda mais, de Mon-

Estado, se do montão de dinheiro que nele gira se for tirando o excesso, ou parte dele, reduzindo-o à baixelas, para que não gire nem represente, o resto do dinheiro do Estado representará sempre o mesmo na razão das suas mercadorias; e de sorte, se evitará que o excesso de dinheiro deste Estado corra para outros ou para a Índia. O dinheiro segue a natureza dos líquidos, que sempre correm para baixo até se porem em equilíbrio ou a nível, se for tirando e estagnado o excesso, ele se conservará sempre em equilíbrio, e não transbordará jamais" (COUTINHO, 1966: 158).

16 "O ouro e a prata tomados como sinal, por isto que não são de uma necessidade absoluta, e só sim de uma comodidade representativa do preço iminente de todas as coisas para uma maior facilidade do comércio, vem a ser de um valor precário e dependente do arbítrio e da estimação dos homens; mas como a estimação dos homens cresce à proporção da abundância dela, assim também a prata e o ouro representam e valem tanto menos quanto eles se fazem abundantes.' (COUTINHO, 1966: 195).

17 O termo inflação não possuía o significado econômico atual na época de Azeredo. Pesquisando nos dicionários de Raphael Bluteau, Vocabulario Portuguez e Latino (1728) e de Antonio de Moraes Silva, Diccionario da lingua portugueza (1789), vemos que o substantivo possuiu o significado médico de uma inflamação, uma inchação ou de um tumor. Já Moraes e Silva também utiliza o termo como sinônimo de orgulho. Os dicionários estão disponíveis online no site <http://www.brasiliana. usp.br/dicionario>. Acessado em 10/09/2011. 
tesquieu. As citações relacionadas ao escocês, na verdade, são para corroborar as ideias presentes em Do Espírito das Leis. Distinções mais sutis surgidas a partir do quarto capítulo do primeiro livro de $A$ Riqueza das Nações, conceitos como preço real, preço nominal, valor de troca e valor de uso, não aparecem na obra do prelado fluminense.

O primeiro texto econômico publicado de Azeredo Coutinho tratava, exatamente, da questão dos preços: sua Memória sobre o preço do açúcar, impressa por ordem da Academia Real das Ciências de Lisboa em 1791. Os contemporâneos a receberam bem, pois, a partir de sua publicação, Azeredo foi aceito como sócio da Academia e, nos anos seguintes, o trabalho foi reimpresso diversas vezes como apêndice ao Ensaio econômico sobre o comércio de Portugal e suas colônias (1794), sem alterações de conteúdo.

A Memória sobre o preço do açúcar veio a público em um momento bem específico: no início dos anos de 1790 o açúcar brasileiro sofreu uma forte valorização no mercado europeu. As explicações para esse fato são conjunturais: tempestades tropicais e políticas desorganizaram a produção canavieira concorrente das colônias francesas, espanholas e britânicas nas Antilhas, até então, grandes polos exportadores do produto para a Europa.

O motivo da publicação do trabalho a que nos referimos é dado pelo próprio autor: devia-se ou não taxar o açúcar? Essa era uma dúvida que rondava os ministros ilustrados portugueses. Segundo Sônia Siqueira, tal taxação foi requerida pela Câmara Municipal de Lisboa, que pretendia tabelar o preço do açúcar no Reino, deixando sua compra mais acessível para comerciantes e consumidores daquela praça (SIQUEIRA, 1964: 354).

O texto de Azeredo, por sua vez, argumenta contra tal medida, defendendo a noção de que a valorização do preço do açúcar é benéfica para os produtores, para os comerciantes que transportavam o produto e para a própria Coroa. O autor ainda cita, em detalhes, a argumentação dos defensores do tabelamento:

Dizem alguns que sim [a taxação devia ser imposta], porque a experiência tem feito ver que um gênero de comércio, levado a excesso, excita logo contra si a rivalidade de outras Nações, e faz que os compradores desse gênero ou se dispensem dele, se podem, ou trabalhem com todas as suas forças para o haverem por um preço mais cômodo e mais barato. 
Que este esforço geral fará descobrir meios de aumentar a abundância desse gênero, até reduzi-lo a um preço tão baixo que faça, se for possível, arruinar esse ramo de comércio da nação ambiciosa que levou o seu gênero a um preço excessivo. (COUTINHO, José Joaquim da Cunha de Azeredo $)^{18}$.

Para Azeredo Coutinho, os argumentos trazidos na citação seriam verdades elementares e inegáveis. Segundo o autor, todos sabiam que o objetivo do comércio era trazer abundância aos países em carestia, eliminando o supérfluo. No entanto, era incompreensível a ideia de que o tabelamento em Portugal fosse uma resposta ao problema, pois o açúcar brasileiro competia com a vantagem de uma concorrência desarticulada no mercado. Pragmático, o bispo indaga qual seria o resultado de taxar unilateralmente um produto que é comercializado por diversas nações concorrentes. Assim, só um improvável acordo geral de produtores seria capaz de tal façanha:

Do expendido fica manifesto o quanto seria prejudicialíssimo a Portugal, e quase mesmo impraticável nas circunstâncias presentes, pôr-se uma taxa na no açúcar, pois que sendo como é um gênero de comércio de quase todas as nações, só a convenção geral de todas as nações é que o pode regular, principalmente quando uma nação não é a só agricultora ou a única senhora desse gênero; de outra sorte, a nação que quiser opor à torrente das outras, ou há de ser pisada pela multidão das concorrentes, ou há de seguir o impulso que elas lhe derem. (COUTINHO, 1966: 180).

Taxando o açúcar para baratear sua compra pelos comerciantes e consumidores do Reino a Coroa faria com que os produtores e os negociantes responsáveis por levar a produção a Lisboa buscassem compensar suas perdas, realizando lucros de forma ilícita. Por que a Coroa Portuguesa não seguia os exemplos da Inglaterra e da Holanda na defesa de seus interesses econômicos? Segundo Azeredo, as duas potências comerciais serviam de exemplo para Portugal em sua estratégia de se assenhorear do comércio do açúcar:

18 COUTinhO, José Joaquim da Cunha de Azeredo. Memória sobre o preço do açúcar. In Obras econômicas de J. J. Azeredo Coutinho (1794-1804). Apresentação de Sérgio Buarque de Holanda. São Paulo: Companhia Editora Nacional, 1966: 175. 
Os ingleses têm levado o seu ferro polido a um preço excessivo; eles já o fazem valer mais do que o ouro: da mesma sorte os holandeses a respeito das suas especiarias, que até muitas vezes queimam e deitam ao mar o excesso delas, para que a sua mesma abundância os não obrigue a abaixar de preço. Eles não temem a concorrência imaginária, esperam que ela seja efetiva, para então governarem a balança a seu favor.

Eles sabem que uma nação, depois que chega a ser única senhora de um certo ramo de comércio, pode então dar a lei como quiser, sem temer os esforços que contra ela fizerem as outras nações. (Ibdem: 175).

Seus comentários atingiam um ponto central no comércio entre a metrópole e suas colônias: com que "justa razão" era possível obrigar negociantes a vender suas mercadorias sem lucro e, talvez, por um valor menor do que aquele que foi pago no Brasil ${ }^{19}$ ? Nessa perspectiva, o agricultor e o comerciante têm sempre interesses harmônicos. Sem o intermediário, que procura continuamente novos mercados, o produtor estará sem estímulos e condenado à estagnação de sua riqueza.

Azeredo se pergunta como é possível evitar que os agricultores não vendam seus produtos para aqueles que tenham as melhores ofertas de compra. Citando o contrabando do tabaco, lembra que "o tabaquista não poupa dinheiro, o contrabandista não teme castigo", o que eleva os gastos públicos para reprimir esse comércio ilegal, abalando a própria autoridade da Coroa (Ibdem: 177).

No último quartel do século XVIII a especialização da produção e o uso de novas técnicas elevaram sensivelmente o custo dos engenhos. Com a concorrência desarticulada o retorno dos senhores de engenho era mais garantido. Essa era uma janela de oportunidade que não podia ser perdida. Como antigo administrador de engenho e ainda diretamente ligado aos interesses de sua família, Azeredo tinha plena consciência disso.

Em sua região natal de Campos dos Goitacazes a indústria açucareira era relativamente recente. Segundo o relato de José Carneiro da Silva existiam ali apenas 55 engenhos e engenhocas em 1769. Entre tal ano e 1778 ergueram-se mais 113 e, de 1778 a 1783, outros 110 (SILVA, 1907: 10-11). Numerosas fortunas, rapidamente desenvolvidas, encon-

19 Tal raciocínio está no centro da defesa do fim dos monopólios que será feita por Azeredo. 
travam-se mal formadas quando Azeredo Coutinho imprimiu sua memória ${ }^{20}$. A concorrência dos produtores caribenhos era o maior estorvo para a expansão dessa fonte de riqueza.

Qual seria, então, o "justo preço" para o açúcar do Brasil? Segundo Montesquieu, "a concorrência é que dá um justo preço às mercadorias e que estabelece as verdadeiras relações entre elas (MONTESQUIEU, 2000: 16). Azeredo, em uma leitura mais superficial, seguiria novamente as ideias do autor francês ao defender que os preços são fixados a partir da oferta e da procura de cada mercadoria ${ }^{21}$. No entanto, ao discutir o tema, o prelado fluminense usa termos como bondade, qualidade, justiça, utilidade, que não aparecem nos textos de Montesquieu.

Com esses indícios, devemos nos perguntar: não será possível associar os argumentos de Azeredo Coutinho a uma tradição de pensamento econômico anterior? No decorrer de seu raciocínio, o bispo utiliza termos que podem ser associados ao pensamento mercantilista típico da Península Ibérica dos séculos XVI e XVII.

Para defender a superioridade do açúcar brasileiro frente a do Oriente, Azeredo Coutinho retoma algumas noções, tais como bondade e qualidade ${ }^{22}$, utilizadas por alguns outros autores. O jesuíta Luis de Molina (1535-1601), por exemplo, professor das Universidades de Coimbra e Évora em fins do século XVI e discípulo do dominicano Francisco de Vitória (1480-1546), faz parte de um grupo de religiosos, como Tomás de Mercado (1530-1576) e Martín de Azpicuelta (1492-1586), que pen-

20 Para melhor entendimento da construção e erosão das riquezas familiares do Norte Fluminense no período abordado (FARIA, 1998).

21 "A utilidade de um lavrador chamará a do outro e os irá multiplicando; esta multiplicidade de vendedores produzirá infalivelmente um melhor mercado, e o comprador terá mais onde escolher em preço e bondade" (COUTINHO, 1966: 129).

O sentido que os tratados econômicos da Escolástica davam para o termo bondade era o de qualidade do que é muito bem feito, bem elaborado ou de grande utilidade. Já a qualidade, era relacionada à eficiência e ao valor do bem material em questão. $\mathrm{O}$ valor é a qualidade que confere a um objeto material a natureza de bem econômico, em decorrência de satisfazer necessidades humanas e ser trocável por outros bens. Para os conceitos de análise econômica dos escolásticos, cf. SCHUMPETER, Joseph Alois. The Scholastic Doctors and the Philosophers of Natural Law. In History of Economic Analysis. New York: Oxford University Press, 2003: 73-143. Para o pensamento econômico de Tomás de Mercado, cf. LIMA, Luís Corrêa. Teologia de mercado: Uma visão da economia mundial no tempo em que os economistas eram teólogos. Bauru/SP: EDUSC, 2001. 
saram a internacionalização do comércio e a rápida entrada de metais preciosos na economia européia sem abandonar os valores cristãos e os preceitos da Escolástica.

Segundo Marjorie Grice-Hutchinson, esses religiosos formavam um grupo de afinidades, não apenas por todos terem ligações com a Universidade de Salamanca, mas também por terem uma pauta de interesses em comum: a questão da propriedade privada, do socorro aos pobres, dos impostos, do preço, do câmbio, do sistema bancário e do lucro. Todas essas eram questões proeminentes da vida econômica no tempo em que o comércio alargava as fronteiras do mundo (GRICE-HUTCHINSON, 1952, 1995).

Segundo Luís Corrêa Lima, a nova dinâmica da atividade mercantil da expansão ibérica levou ao surgimento de questões práticas que o pensamento econômico escolástico tradicional - inspirado em obras como A Ética a Nicômaco, de Aristóteles, e a Suma Teológica, de Santo Tomás de Aquino - simplesmente não respondiam. Tomás de Mercado, por exemplo, escreveu sua Suma de tratos y contratos por encomenda do Consulado dos Mercadores, uma guilda de comerciantes de Sevilha. Os membros do Consulado queriam um manual de negócios que os permitissem redigir contratos e fechar negócios sem cair no pecado da usura. O bom mercador cristão deveria saber o que era justo nos negócios, para não correr o risco de perder o "bem eterno tratando do temporal" ${ }^{\prime 23}$.

A difusão da obra dos autores de Salamanca pela Europa se deu basicamente nas aéreas de credo católico e nas regiões sob o jugo político da Coroa espanhola. Segundo Schumpeter, é possível encontrar citações da obra de Suárez nos trabalhos de Hugo Grotious (1583-1645) e nos de Samuel Pufendorf (1632-1694) (SCHUMPETER, 2003: 102).Já no século XVIII, ninguém menos do que Campomanes citava Tomás de Mercado em seus ensaios (CASTRO, 1996: 34-35).

Trabalhos de Luís de Molina eram leituras obrigatórias na Universidade de Coimbra até a reforma de 1772. No entanto, segundo Teófilo Braga, os livros de Molina nunca deixaram de estar acessíveis nas estantes da biblioteca da universidade (BRAGA, 1898). Seus três tratados

23 (LIMA, 2001:11-12) para o pensamento econômico da escolástica medieval, ver LE GOFF, 2004; Langholm, 1992. 
econômicos: A teoria do justo preço; Tratado sobre empréstimos e a usura e Tratado sobre o câmbio trazem ideias que podem elucidar alguns pontos da argumentação de Azeredo Coutinho.

Molina possuía uma análise avançada sobre a regulação de preços, sendo possível dividir sua argumentação em algumas ideias fundamentais. Uma delas é que a regulação dos preços por parte das autoridades provoca a aparição de preços errôneos e distorções no mercado, indo contra a justa razão que deveria pautar a administração dos assuntos de Estado. Na medida em que os preços dos bens estão relacionados entre si, não fazia sentido regular apenas os preços dos bens finais. $\mathrm{O}$ autor ilustra essa tese mediante um exemplo: se a autoridade deseja regular o preço do pão e dos sapatos, também deverá manter o controle dos preços da farinha e do couro. Caso não seja assim, produziriam desajustes entre a produção e a distribuição. Além disso, a regulação de preços incentivava a corrupção das autoridades públicas encarregadas de oficializá-la. Essa regulação poderia conduzir à fraude e ao descumprimento da lei por parte dos agentes econômicos, minando o respeito às leis da Coroa e da Igreja (MOLINA, 1981).

No segundo e no terceiro capítulo de sua Instrucción de Mercaderes, Luís Saravia de la Calle aborda a questão do justo preço. Excluindo toda a malícia e desonestidade, o preço justo era aquele estabelecido no mercado por vendedores e compradores honestos no momento de contratação do negócio, em moeda corrente, considerando-se as especificidades de cada transação. Essas contingências seriam baseadas na dificuldade de obtenção e na disponibilidade de cada mercadoria particular e, ainda, no benefício e na satisfação de seu uso. Saravia de la Calle fazia também uma distinção interessante, dando ênfase ao momento no qual o contrato era assinado, pois o desgaste dos produtos durante o transporte poderia diminuir ou aumentar seu preço. Além disso, os preços poderiam variar entre os mercados ${ }^{24}$.

Em De Justitia et Iure (1553), Domingo de Soto vai além ao colocar a seguinte questão: os preços deveriam ser estipulados pelo julgamento dos próprios mercadores? A resposta do autor é negativa. Desejos e

24 A Instrucción de Mercaderes (1544) foi publicada originalmente em Medina del Campo. Utilizamos aqui a reprodução dos capítulos 2 e 3 que estão anexados ao livro de GRICE-HUTCHINSON (1952: 79-82). 
conveniências individuais não podem exceder às prerrogativas da comunidade. Assim, o preço deveria ser estabelecido pela estimação da mercadoria por todos os vendedores e compradores. No entanto, existiam parâmetros a serem seguidos. O primeiro deles estabelece o preço da mercadoria não por sua natureza, mas pela necessidade que o mercado possui desse item em particular. O segundo, por sua vez, considera a demanda pelo item em questão, sua abundância ou escassez.Também era necessário considerar o trabalho, o risco e as dificuldades de cada mercador ao realizar seu negócio ${ }^{25}$.

Ao abordar esse tema, Odd Langholm faz uma observação pertinente: os escolásticos medievais estavam imersos em um universo mental no qual os compradores e os vendedores eram "obrigados" a atuar pelo bem comum e a aceitar os custos de transação no limite de seus interesses individuais. Autores como Molina e seus contemporâneos romperam com essa abordagem ao defender que o preço justo nem sempre seria o ideal para toda a comunidade. Aqui vemos uma defesa da legitimidade da busca do lucro dentro de um mercado com leis de conduta estabelecidas ${ }^{26}$.

Louis Baeck destaca dois aspectos fundamentais das obras de Molina e seus contemporâneos. Primeiro, a cura animorum, ou seja, o dever de zelar pelas consciências dos fiéis. Os tratados de Molina serviriam para os comerciantes com escrúpulos de consciência e para confessores necessitados de guias de comportamento. Por trás dessa postura estava o temor de uma expansão descontrolada da especulação e de atitudes desleais, passíveis de levar a sociedade a uma ruptura através da subversão de seus aspectos morais. Essa geração de escolásticos radicalizou os conceitos de voluntarismo individual e de humanismo democrático, desenvolvidos pelos franciscanos nos séculos XIII e XIV. Os salmantinos privilegiaram a liberdade de consciência e a responsabilidade social de cada indivíduo. A máxima expressão política dessas ideias é o conceito de pacto social entre a autoridade estabelecida e as gentes.A teoria de direito natural em questão observa e preserva os direitos dos indivíduos

25 SOTO, Domingo de. "Lib. IV, Q. 2, Art. III". In De Justitia et Jure. Salamanca, 1553:546-549. Existe uma tradução inglesa no apêndice documental do livro de Marjorie Grice-Hutchinson, 1959: 83-88.

26 (LANGHOLM, 2006:77-99) para a discussão em torno do preço justo, ver, ainda ROOVER (1958). 
frente aos poderes da ordem feudal, do absolutismo imperial e, ainda, da autoridade da própria Igreja. Assim, dava-se ênfase nas liberdades individuais de pensamento e de consciência (BAECK, 1998: 173-174).

Essas ideias estavam baseadas no Molinismo, a interpretação filosófica de Luis de Molina acerca das relações entre a onisciência divina e a liberdade e responsabilidade do agir humano. Se o domínio de Deus é universal, absoluto e atemporal, então como o Todo Poderoso interage nos atos livres dos homens sem retirar sua liberdade?

Segundo Lúcio Craveiro da Silva, os teólogos contemporâneos de Molina reconheciam, em Deus, dois tipos de consciência: a "simples inteligência", através da qual Deus conhecia todos os seres, e a "ciência da visão", pela qual conhecia todas as coisas passadas, presentes e futuras. Para Molina, Deus conhecia as ações futuras dos homens livres pela "ciência média". Através dela, o Todo Poderoso tinha um real conhecimento infalível das atitudes individuais futuras livremente condicionadas. Dessa maneira, Deus está presente e consciente em todas as ações humanas, sejam elas livres ou não. Seu concurso nos atos livres é simultâneo, mas indiferente. Molina conciliou a causalidade universal de Deus com a liberdade do homem (SILVA, 2001: 547-558).

Os salmantinos aplicavam as ideias individualistas para a ação dos agentes econômicos no mercado. Uma das consequências disso era a crítica aos monopólios, que distorciam as relações comerciais e não permitiam que os indivíduos realizassem seus interesses de forma legítima ${ }^{27}$. Complementando essa ideia, a estimativa do preço justo por agentes livres era um instrumento que ajudava a combater a exploração individual a partir de suas necessidades de subsistência (PERROTA, 2000). O monopólio, por sua vez, só era justificado em raríssimas circunstâncias, mais especificamente, naquelas em que ele favorecesse toda a comunidade e não alterasse o preço justo das mercadorias.

A versão salmantina do mercado, baseada na tradição escolástica, era palatável às ideias e objetivos de Azeredo Coutinho. Assim, o comportamento dos agentes econômicos não cairia no vale-tudo das paixões $\mathrm{e}$ dos interesses estritamente comerciais. Um bom exemplo da presença de tal ideia é a forma como o prelado critica os contrabandistas: o contrabando não é apenas um crime contra a ordem pública, mas um ato de

27 Sobre a ilegitimidade dos monopólios, cf. DE ROOVER, 1951. 
subversão dos valores que regulam o bom funcionamento do sistema de $\operatorname{preços}^{28}$.

A ideia de mercado dos setecentistas é um pouco distinta, sendo baseada em noções de direito natural que são fundamentais para o pensamento fisiocrático e para o liberalismo de Adam Smith ${ }^{29}$. Partindo do argumento de que Deus criou o mundo perfeito e bondoso e de que tudo que há nele está submetido a leis naturais para proporcionar a conservação e a felicidade dos homens os entusiastas dessa versão do direito natural acreditavam que o plano divino só iria se realizar quando cada indivíduo agisse conscientemente para melhorar sua própria condição.

28 Azeredo Coutinho não considerava o contrabando como um fator desestabilizador das relações comerciais entre Portugal e o Brasil. Em relação aos comentários de habitantes das Minas de que alguns representantes da Coroa eram os principais culpados pelo descaminho, Azeredo apregoa seu ceticismo: "Confesso que não sei de semelhante fato, e até me parece que posso afirmar que é falso na parte em que se diz feito com autoridade dos magistrados, pois que não posso persuadir que homens sábios, dotados de justiça e probidade, concorram para um fato que, além de ser contrário à boa fé devida às nações amigas, seria um grande erro de política, e muito prejudicial aos seus mesmos interesses, por isso que davam lugar a Portugal a autorizar os seus ministros para usarem também de represálias contra tais nações". (COUTINHO, 1966: 202-203). A situação do contrabando era bem mais complexa do que pensava Azeredo. Paulo Cavalcante estudou casos de descaminho na primeira metade do século XVIII que contaram com, no mínimo, a leniência de alguns funcionários régios. A diminuição do volume da produção mineira pode ter sido acompanhada pela redução proporcional do contrabando, mas negar sua existência é irreal (CAVALCANTE, 2006). Fernando Novais, por sua vez, defende que "as tensões da concorrência, a luta das potências, o contrabando eram processos que operavam dentro do mesmo sistema básico, não negavam o sistema”. Nessa interpretação, os contrabandistas tinham como cálculo os imensos ganhos das brechas do Exclusivo Colonial.Ainda segundo Novais, "em suma, licenças, concessões, contrabando, parecem-nos fenômenos que se situam mais na área da disputa entre as várias metrópoles européias para se apropriarem das vantagens da exploração-colonial - que funciona no conjunto do sistema, isto é, nas relações da economia central européia com as economias periféricas. Não atingem, portanto, a essência do sistema de exploração colonial" (NOVAIS, 1979: 72-92).

29 A novidade do direito natural estava na ideia de que existe um sistema de leis - sem nenhum tipo de legislação concreta - formado por normas e regras universalmente aceitas, baseadas na natureza humana e nas necessidades coletivas da sociedade. Essa noção de direito vai criar uma nova convicção de que existe uma harmonia natural que exclui todo tipo de arbitrariedade e desígnio divino preestabelecido e dará instrumentos para os indivíduos perceberem a ordem que os governam, tornando-os responsáveis por seus próprios destinos (TUCK, 1979). 
No entanto, para o advento desse mundo organizado a partir de ações individuais eram necessárias instituições conformadas às liberdades naturais: no plano da política interna, a liberdade dos agentes econômicos e um Estado que assegurasse o funcionamento do mecanismo natural; no plano externo, certa liberdade de comércio bastaria para harmonizar os diversos interesses em questão. Assim, a ação individual e as instituições a ela ajustadas conduziriam as nações à riqueza, permitindo o usufruto dos benefícios que foram colocados à disposição dos homens desde o início dos tempos (HONT, 1983).

Nesse aspecto, as diferenças entre o raciocínio de Azeredo Coutinho e o de Adam Smith estão no fato de que, para o prelado luso-brasileiro, o mercado é o lugar da ordem e a ética cristã deve nortear a atuação de cada indivíduo. Comportamentos "egoístas" ou vícios privados não eram, então, correspondidos por virtudes públicas. Além disso, para Azeredo, a liberdade e o interesse individual devem ser suspensos quando o bem comum está em risco (GIANNETTI, 2007).

A convicção de Azeredo em renegar uma abordagem do jusnaturalismo absoluto através de suas propostas de valorização do direito individual em qualquer circunstância impedia-o de compreender, em sua plenitude, os instrumentos de análise econômica da fisiocracia e da economia política liberal. Os supostos aspectos liberais - como a crítica ao tabelamento de preços, o combate a certos monopólios, a concepção da economia como um sistema impessoal baseado na lei da oferta e da demanda - presentes na obra do inquisidor economista já faziam parte do instrumental teórico dos autores mercantilistas desde o século XVI. Foi a preferência de Azeredo pela primazia do direito da sociedade e pelo bem comum frente aos direitos individuais que levou Sérgio Buarque de Holanda a aproximar Azeredo dos autores do Cameralismo alemão (HOLANDA, apud COUTINHO, 1966: 26).

No entanto, essa influência não é tão decisiva. O relativismo que Azeredo pregava para o exercício do direito o afastava da sistematização jurídica defendida pelos cameralistas alemães. A segunda citação da obra do Barão de Bielfeld, por exemplo, é uma crítica pontual contra a indústria do luxo, setor que poderia desviar recursos preciosos da economia. No entanto, em uma passagem típica de seu pragmatismo brutal, Azeredo defende outros tipos de manufaturas: 
As manufaturas que só pedem braços sem muito engenho, nem muita arte, as ordinárias, que mais convém ao povo, que é o grande consumidor do Estado, são as que mais convêm a Portugal. As mulheres, os rapazes, os velhos, os estropiados, todos acham nestas manufaturas um gênero de trabalho proporcionado às suas forças. (COUTINHO, Ibdem: 159).

Para o Reino, o ideal seria constituir manufaturas de primeira necessidade, aquelas cujos produtos vestem a tropa e armam as marinhas e o exército nacional. Outros setores também não deveriam ser desprezados: cordoarias, todo o tipo de gêneros de couro, de papel, entre outros.

Já a última contribuição do cameralista talvez seja a mais importante. $\mathrm{O}$ desenvolvimento econômico não era compatível com a aplicação de mais tributos nas atividades econômicas ${ }^{30}$, muito menos na manutenção dos estancos e dos contratos régios ${ }^{31}$. Um exemplo histórico pertinente foi o do francês Jean-Baptist Colbert (1619-1683), ministro que racionalizou a tributação francesa para financiar as intermináveis guerras de Luís XIV. Assim, o equilíbrio entre os tributos e a produção deveria pender para a última, a opulência do soberano deve corresponder à riqueza de seus súditos ${ }^{32}$.

30 "A extinção dos direitos das madeiras do Brasil neste Reino não se pode dizer que é uma perda para o Erário Régio; é um erro muito grosseiro e, mesmo, destruidor do bem do Estado, querer aumentar os rendimentos do Soberano sem aumentar a opulência geral do Estado. A economia de um Reino é muito diferente da de um particular; a razão é clara: 1) $O$ dinheiro que sai da bolsa de um particular sai para sempre; o que sai dos cofres do Estado entra todo no Estado; e é muito raro que este dinheiro passe por alguma mão sem que deixe algum proveito. 2) Os meios de que se vale um particular são sempre limitados; os de um Estado bem governado não têm limites. 3) A maior parte das despesas de um particular tendem a se procurar mais comodidades e mais prazeres. Todas as despesas públicas, pelo contrário, tendem ou à conservação imediata do Estado, ou a aumentar a sua prosperidade, as suas forças e a sua opulência. É necessário, enfim, semear para colher." (COUTINHO, Ibdem: 134).

31 Os estancos régios eram os monopólios da Coroa: o do pau-brasil (1501), o da pesca da baleia (1603-1798), o do tabaco (1642-1820), o do sal (1658-1801) e o dos diamantes (1731-1822). A coroa esporadicamente transferia monopólios a particulares através de arrendamentos sob a forma de contratos (FURTADO, 1995).

32 "Luís XIV não seria grande se não tivesse a seu lado o sábio Colbert que, no mesmo tempo em que a França já quase sem forças parecia sucumbir com o peso das suas vitórias, a salvou pelo meio dos infinitos canais que ele abriu à indústria da sua nação; o ser grande homem de Estado não consiste em meios de impor mais e mais tributos; consiste, sim em descobrir meios de fazer rebentar de novo perenes fontes de riqueza, que fertilizem o Estado por toda parte." (COUTINHO, 1966: 135). 
Se a riqueza está baseada na posse de bens móveis, os agentes econômicos deveriam ter liberdade para buscar mais efeitos e atingir seu enriquecimento, pois a riqueza dos indivíduos é a base da prosperidade das nações. No caso de um império colonial, a riqueza das colônias está na base da prosperidade das suas respectivas metrópoles.

Aqui temos uma contradição que sempre embaralhou os estudiosos da obra de Azeredo: paladino do fim dos monopólios, o prelado fluminense era um defensor do exclusivo colonial. Este último seria o marco regulatório das relações econômicas entre as diversas partes dos impérios coloniais. Para Azeredo Coutinho, o exclusivo comercial não é sinônimo de monopólio. A pista para a compreensão desse dilema se inicia a partir de seu modelo de funcionamento de uma monarquia justa e virtuosa. Devemos imaginar uma grande embarcação e:

Nela veria Vossa Alteza um grande todo composto de partes diferentes, mas tão bem construídas e ajustadas entre si que todas se moviam com uniformidade aos mais pequenos impulsos do seu leme, uma das mais pequenas partes de seu todo: tal é uma monarquia bem ordenada, quando cada uma das suas partes enche o fim de seu destino; uma só parte desarranjada destruiria toda a máquina; fora do seu lugar o leme, a nau seria submergida.

Vossa Alteza veria na sua nau que o governo e os movimentos dela não eram dirigidos pelo acaso, nem por algum ignorante que primeiro se apresentava, mas sim por u'a mão hábil, prudente e forte, reconhecida por uma experiência longa na grande arte do governo. (COUTINHO, Ibdem: 63).

O instrumento básico para os soberanos resguardarem as riquezas de seus impérios de potências rivais é a capacidade de ter exclusividade no comércio com suas colônias. $\mathrm{O}$ exclusivo era uma rede de reciprocidades que unia e dava coerência a todas as partes da Monarquia.A metrópole deveria interagir com as colônias, respeitando suas especificidades. Azeredo tipifica as colônias portuguesas de duas formas: as das Índias Orientais e da costa da África tinham por objetivo o comércio; os estabelecimentos da América, por sua vez, possuíam, além do comércio, diversas culturas ${ }^{33}$.

A costa da África possuía um trato fundamental para o Império, a saber, o comércio do resgate de escravos, que eram trocados pelo taba-

33 (COUTINHO, Ibdem: 138), essa distinção é destacada por ARRUDA (1991). 
co brasileiro ${ }^{34}$. Manter portos seguros na costa africana era estratégico para o desenvolvimento da agricultura no Brasil. Assim, a Coroa deveria se comprometer em manter uma frota guarda-costas de prontidão para defender os interesses comerciais portugueses. As possessões de São Tomé e Príncipe e de Angola, que esporadicamente serviam de abrigo seguro para navios de outras bandeiras, deveriam ter um tributo de ancoragem, não somente para utilidade do Erário Régio, mas também para que não entrassem em concorrência com os negociantes portugueses. Na costa de Zanzibar, Moçambique poderia fornecer produtos com grande procura em Goa. O marfim, o ouro e os escravos moçambicanos tinham um mercado garantido na Índia (COUTINHO, Ibdem, 148).

Azeredo acreditava que o Oriente poderia assistir ao ressurgimento de uma nova Goa Dourada. O caminho estava aberto aos portugueses. A concorrência estabelecida na região não era militar, mas comercial. Para perseverar, os portugueses só dependiam de sua própria indústria. A rede de portos e feitorias dos portugueses necessitava apenas de investimentos para fazer frente à força das companhias comerciais dos concorrentes ingleses, holandeses e franceses. Criticando mais uma vez o sistema de contratos Azeredo via como principal obstáculo para o

34 Azeredo não perde outra oportunidade para criticar os monopólios. A concorrência de outras nações, os "insultos de negociantes estrangeiros" e o monopólio do tabaco deixavam a posição dos traficantes portugueses enfraquecida nas transações de resgate de escravos. Segundo Azeredo, "a paixão que os negros da costa da África têm pelo tabaco do Brasil, sempre deu aos portugueses uma grande superioridade no comércio daquela costa: as outras nações que ali faziam o comércio eram obrigadas a fazê-lo do refugo dos portugueses; hoje, porém, que já ali se fazem plantações, é necessário não deixar perder as portuguesas, e livrá-las de todos os embaraços do monopólio, do qual, logo que o tabaco seja livre, será de uma utilidade suma, não só para os agricultores e comerciantes deste gênero, mas também para a Fazenda Real; fazendo-se o cálculo do número das arrobas de tabaco que todos os anos saem das alfầndegas do Brasil, dividido pela soma total que o monopólio deste gênero produz atualmente à Fazenda Real, o quociente dará o imposto que cada arroba ou rolo de tabaco deverá pagar na saída da alfândegas do Brasil e na entrada destas, imposto que sempre irá crescendo na razão das entradas e saídas, como todos os gêneros alfandegados, sem que seja preciso aumentarem-se os oficiais das alfầndegas, nem o infinito número dos empregados no serviço dos monopolistas, nem dos seus privilegiados sem número, posto que se fiquem conservando os Tribunais Régios e os ministros de uma tal administração,e despachos para o expediente de tão grande ramo de comércio." (COUTINHO, 1966: 143). 
aumento dos lucros os poucos fundos que os agentes privados monopolistas possuíam para investir na compra de produtos locais ${ }^{35}$.

Ainda analisando a situação do Estado da Índia, o prelado ataca aquela que talvez seja a principal questão de seus contemporâneos e antepassados acerca do comércio oriental: o fato de este comércio ser deficitário para os europeus ${ }^{36}$. O insight de Azeredo em tal questão será posteriormente abstraído para a relação de Portugal com a América. As companhias comerciais europeias atuantes no Oriente "importavam infinitamente mais mercadorias das Índias para as suas nações respectivas do que elas exportam." Esse comércio era um grande escoadouro de moedas e metais preciosos para os europeus. No entanto, os custos dessa importação eram superados, inúmeras vezes, por suas respectivas reexportações (COUTINHO, 1966: 150).

Assim, por que não aplicar esse princípio ao comércio americano? "Portugal, quanto mais dever às suas colônias tanto será mais rico". Esse será o mote da política colonial de Azeredo. Em um mundo em transformação, no qual o Antigo Sistema Colonial passou a ser criticado em ambos os lados do Atlântico, a única forma de manter o sistema unido seria continuar levando prosperidade aos produtores americanos.

Para Azeredo, o problema era político, já que, para ele, a economia ia bem. Então, como bloquear a influência das abomináveis ideias francesas nos territórios americanos? Ideias em torno da inevitabilidade da independência da América Latina - defendidas por Raynal ${ }^{37}$ e por De

35 Para as desventuras do império asiático português cf. Subrahmanyam (1994; 1995).

36 Azeredo poderia ter chegado a essa conclusão lendo o próprio Montesquieu, defensor da ideia de que esse comércio era deficitário devido à exportação europeia de metal precioso americano ainda no século XVIII: "A prata extraída das minas da América, transportada para Europa, enviada ainda daí para o Oriente, favoreceu a navegação da Europa: é uma mercadoria a mais que a Europa recebe em troca da América e que envia em troca para as Índias." (Montesquieu, 2000: 72). Fernand Braudel mostra a origem americana de grande parte das rupias indianas e também defende a ideia de um comércio europeu deficitário com o Oriente (BRAUDEL, 1996, $3^{\circ}$ Volume: 455-456).

37 Para as ideias anticolonialistas do abade Raynal e suas impressões acerca da colonização portuguesa no Brasil, cf. CAVALCANTE (1998: 11-33). Já para a leitura e recepção dos luso-brasileiros a respeito das ideias de Raynal e de sua interpretação acerca da Independência das Treze Colônias (1776), cf. FIGUEREDO (1993: 1-52). 
Pradt $^{38}$ - deveriam ser combatidas a partir de políticas públicas que tornassem os laços entre o Reino e a América insubstituíveis ${ }^{39}$.

Tais laços seriam revigorados pela manutenção de seu tripé fundamental: a preservação do exclusivo comercial, com a valorização de suas vantagens recíprocas para reinóis e americanos; a defesa e conservação do tráfico de escravos, fonte básica de mão de obra para a economia colonial e, finalmente, a reafirmação da autoridade régia no ultramar, exemplificada na obra de Azeredo a partir de uma releitura do padroado régio, prerrogativa que deveria sair da jurisdição da Mesa da Consciência e Ordens para a esfera de atuação do Conselho Ultramarino.

Sobre o exclusivo comercial, Azeredo Coutinho reconhece que tal elemento poderia trazer malefícios para os produtores americanos ${ }^{40}$. Nesse aspecto, ele critica aqueles que viam as colônias apenas como uma economia complementar à europeia, passível de ser explorada indefinidamente ${ }^{41}$. Como já foi dito, para o autor, o exclusivo não era sinônimo

38 Azeredo cita em mais de uma ocasião o livro Les Trois Âges des Colonies ou de Leur État Passé, Présent et à Venir. Par M. De Pradt. Membre de L'Assemblée Constituante. À Paris, Chez Giguet et $\mathrm{C}^{\mathrm{ie} I m p r i m e u r s-L i b r a i r e s, ~ R u e ~ d e s ~ B o n s-E n f a n s, ~} \mathrm{n}^{\circ} 6$, au coin de celle baillif, 1801-1802. A obra estava dividida em três tomos: os dois primeiros são estratos do trabalho de Raynal acerca dos estabelecimentos europeus nas Américas. O terceiro é uma análise da colonização europeia partindo do pressuposto que "L'Europe et ses colonies sont dans une position inverse, sans être contradictoire". O autor francês vê a independência das colônias como algo inevitável e sua proposta é preparar a separação dos impérios americanos de forma racional. Além disso, assim como Raynal, De Pradt destaca a revolução das 13 Colônias como um exemplo. Apesar da escravidão, os americanos já estavam maduros para tornaremse independentes. Azeredo criticava essa "suposta" inevitabilidade e os argumentos "racionais" do francês. Para uma abordagem inicial do pensamento de De Pradt, cf. MOREL (2005: 617-626). Cf, ainda, PIMENTA (2010).

39 Um fato curioso, mas compreensível, é a ausência de qualquer referência à Independência das Treze Colônias na obra de Azeredo. Como explicar o fato de uma colônia ter se tornado independente, dada a manutenção da escravidão e o controle do poder político pelos grandes proprietários e pelos letrados? Essa questão deve ter assombrado o futuro bispo de Olinda da mesma forma que espantava os secretários da Coroa em Lisboa.

40 Montesquieu também irá abordar o tema:"A desvantagem das colônias, que perdem a liberdade de comércio, é visivelmente compensada pela proteção da metrópole, que a defende com suas armas, ou mantém com suas leis." (Montesquieu, 2000: 60).

41 "A Metrópole e as colônias, principalmente a respeito da agricultura e de tudo o que é produção da terra, se deve considerar com um só prédio de agricultor, cujo fim é conservar a sua casa em abundância e ter um grande supérfluo para vender aos estranhos. Ao possuidor de muitas quintas não importa, nem deve importar, que 
de monopólio. Da obrigatoriedade dos americanos negociarem com a metrópole deveria haver a contrapartida desta última em oposição ao avanço de potências rivais, instituições fiscais e jurídicas que facilitassem a produção agrícola e garantissem os ganhos privados. Além disso, a segurança de que as bases da prosperidade americana seriam mantidas, inclusive, com a manutenção do tráfico de escravos ${ }^{42}$.

A prosperidade dos súditos americanos os afastaria de qualquer tipo de ideias "perniciosas", e o exemplo norte-americano continuaria sendo ignorado pela maioria:

O homem que vive no meio da pobreza, da opressão e da miséria, amaldiçoa ainda aqueles que o geraram, aborrece a vida, revolta-se contra todos, contra si mesmo, mata-se e despedaça: o homem enfim, que não tem que perder, é o mais atrevido e o mais insolente, a tudo se atreve, nada lhe resiste.

E, pelo contrário, o homem que vive na abundância logo se lembra de uma companhia honesta, que lhe seja amável e que o ajude a viver contente e quando se vê reproduzido em seus filhos, adora o Criador e beija a mão benfeitora que o protege, respeita a religião, respeita as leis e é o primeiro que se interessa na conservação da paz pública, da qual necessariamente depende a sua particular e a da sua família.

Só teme quem tem que perder; quem mais te que perder, mais teme; quem mais teme, mais obedece; é, pois, necessário que os interesses da Metrópole sejam ligados com os das colônias, e que estas sejam tratadas sem rivalidade. Quanto os vassalos são mais ricos, tanto o soberano é muito mais. (COUTINHO, 1966: 156, Grifos Nossos).

Talvez esse seja o maior mérito do Ensaio econômico sobre o comércio de Portugal e suas Colônias para seus contemporâneos. Assim como D.

esta ou aquela lhe renda mais: só, sim, que todas lhe rendam muito." (COUTINHO, 1966: 153).

42 "Estes benefícios pedem iguais recompensas e, ainda, alguns justos sacrifícios; e, por isso, é necessário que as colônias também, da sua parte, sofram: 1) que só possam comerciar diretamente com a Metrópole, excluída toda e qualquer outra nação, ainda que lhes faça um comércio mais vantajoso; 2) que não possam as colônias ter fábricas, principalmente de algodão, linho, lã e seda, e que sejam obrigadas a vestirse das manufaturas e da indústria da indústria da Metrópole. Desta sorte, os justos interesses e as relativas dependências mutuamente serão ligadas." (COUTINHO, Ibdem: 155). 
Luís da Cunha, Azeredo enxergou o Império português como uma grande economia com partes distintas que se complementavam. $\mathrm{O}$ papel da América era desenvolver suas culturas para abastecer o Reino de matérias primas e alimentos, gerando lucros com a reexportação de seus produtos no mercado europeu. Além disso, o mercado consumidor americano teria privilégios para a produção reinol ${ }^{43}$.

Para manter a prosperidade das colônias da América Portuguesa um ponto era fundamental: proteger o fluxo de mão de obra escrava para o trabalho no campo. Este fluxo sofria um ataque duplo: o interesse material dos comerciantes britânicos ávidos pelo controle de pontos de fornecimento na costa da África e as maquinações da "seita dos filósofos". Tais filósofos desvirtuavam o direito ao advogar em favor do indefensável, ou seja, do sistema de pactos sociais e da igualdade absoluta entre os homens. Esse é o próximo front do debate intelectual que Azeredo irá se engajar.

\section{Referências bibliográficas}

ALDEMAN, Jeremy. Sovereignty and revolution in the Iberian Atlantic. Princeton and Oxford: Princeton University Press, 2006.

ARRUDA, José Jobson de Andrade. Colonies as mercantile investiments: the LusoBrazilian Empire (1500-1808). In TRACY, James D. The political economy of merchant Empires. Cambridge: Cambridge University Press, 1991.

BAECK, Louis. Monetarismo y teorías del desarrollo en la Península Ibérica en los

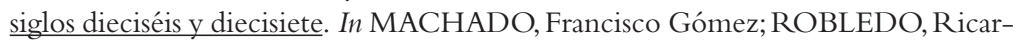
do (eds). El pensamiento económico en la Escuela de Salamanca: una visión multidisciplinar. Salamanca: Ediciones Universidad de Salamanca, 1998.

BRAGA, Teófilo. História da Universidade de Coimbra nas suas relações com a instrução pública portuguesa. (Tomo III. 1700-1800). Lisboa: Academia das Ciências, 1898.

43 "É certo que, se à agricultura e à produção dos gêneros das colônias se der toda a extensão de que elas são capazes, a Metrópole não os poderá consumir todos, nem dar-lhes em gêneros e manufaturas um igual valor das suas receitas, e que por isso seja necessário saldar a sua conta a dinheiro. Mas, que prejuízo se seguirá disto à Metrópole? Quanto mais abundar em gêneros das colônias, tanto ela terá mais que vender aos estrangeiros. Os gêneros das colônias são preciosos, são da primeira necessidade; os estrangeiros necessitam, não se podem dispensar deles." (COUTINHO, Ibdem: 154). 
BRAUDEL, Fernand. Civilização material, economia e capitalismo. Séculos XV-XVIII. São Paulo: Martins Fontes, 1996, $3^{\circ}$ Volume (O Tempo do Mundo).

CARDOSO, José Luís. O Pensamento Econômico em Portugal nos finais do século XVIII (1780-1808). Lisboa: Editorial Estampa, 1989.

CASTRO, Concepción. Campomanes: Estado y reformismo ilustrado. Madri: Alianza Universidad, 1996.

CAVALCANTE, Berenice. Dilemas e paradoxos de um filósofo iluminista. In RAYNAL, Guillaume-Thomas François. $\mathrm{O}$ estabelecimento dos portugueses no Brasil. Rio de Janeiro / Brasília: Arquivo Nacional / Editora UnB, 1998.

CAVALCANTE, Paulo. Negócios de trapaça: caminhos e descaminhos na América Portuguesa (1700-1750). São Paulo: Editora Hucitec, 2006.

COUTINHO, José Joaquim da Cunha de Azeredo. Ensaio econômico sobre o comércio de Portugal e suas colônias. Lisboa: Banco de Portugal, Coleção de Obras Clássicas do Pensamento Econômico Português,Volume 3, 1992.

Obras econômicas de Coutinho (1794-1804) Apresentação de Sérgio Buarque de Holanda. São Paulo: Companhia Editora Nacional, 1966.

In Coleção de alguns manuscritos curiosos do Exmo. bispo d'Elvas, depois inquisidor geral dos quais posto que já se tenham publicado alguns no periódico denominado $O$ Investigador português... outro no periódico denominado Mnemozine Luzitana... com tudo foram sem nome do autor; outros que ainda se conservam manuscritos se vão agora fazer públicos pelo meio da imprensa. Londres: Impresso por L. Thompson, 1819.

CUNHA,Alexandre Mendes. Police Science and Cameralism in Portuguese Enlightened Reformism: economic ideas and the administration of the state during the second half of the 18th century. e-JPH.Vol. 8, number 1, Summer 2010.

DE ROOVER, Raymond. Monopoly Theory Prior to Adam Smith: a revision. In The Quarterly Journal of Economics, vol. 65, n.4, (Nov., 1951).

DEYON, Pierre. O Mercantilismo. $4^{a}$ edição. São Paulo: Perspectiva, 2009.

FARIA, Sheila de Castro. A Colônia em movimento: fortuna e família no cotidiano colonial. Rio de Janeiro: Nova Fronteira, 1998.

FIGUEREDO, Luciano Raposo de Almeida; FILHO, Oswaldo Munteal. Prefácio: a propósito do Abade Raynal. In RAYNAL, Guillaume-Thomas François. A Revolução da América. Rio de Janeiro: Arquivo Nacional, 1993.

FURTADO, Celso. Formação Econômica do Brasil. 25 Edição. São Paulo: Companhia Editora Nacional, 1995.

GIANNETTI, Eduardo. Vícios privados, benefícios públicos?: a ética na riqueza das nações. São Paulo: Companhia das Letras, 2007.

GRICE-HUTCHINSON, Marjorie. Ensayos sobre el pensamiento económico en España. Madrid: Alianza Editorial, 1995.

. The School of Salamanca: Readings in Spanish Monetary Theory (1544-1605). Oxford: Clarendon Press, 1952. 
HESPANHA, Antonio Manuel. Por que é que foi "portuguesa" a expansão portuguesa? Ou o revisionismo nos trópicos. In BICALHO, Maria Fernanda; FURTADO, Júnia Ferreira \& SOUZA Laura de Mello (orgs). O Governo dos Povos. São Paulo: Alameda, 2009.

HONT, Istvan; IGNATIEFF, Michael. Needs and justice in the Wealth of Nations: an introductory essay. Wealth and virtue: the shaping of political economy in the Scottish enlightenment. Cambridge: Cambridge University Press, 1983.

LANGHOLM, Odd. Price and market manipulation. In The legacy of Scholasticism in economic thought: antecedents of choice and power. Cambridge: Cambridge University Press, 2006.

LANGHOLM, Odd. Economics in the Medieval Schools. Wealth, Exchange, Value, Money and Usury according to the Paris Theological Tradition (1200-1350). Leiden, New York, Köln: E. J. Brill, 1992.

LE GOFF, Jacques. A bolsa e a vida: a usura na Idade Média. São Paulo: Editora Brasiliense, 2004;

LIMA, Luís Corrêa. Teologia de mercado: Uma visão da economia mundial no tempo em que os economistas eram teólogos. Bauru/SP: EDUSC, 2001.

MOLINA, Luís de. La Teoría del Justo Precio. Ed. de F. Goméz Camacho. Madrid: Editora Nacional, 1981.

MONTESQUIEU. Do Espírito das Leis. São Paulo: Editora Nova Cultural, 2000, (Coleção Os Pensadores), Volume II.

MOREL, Marco. A independência no papel: a imprensa periódica. In JANCSO, István (org.). Independência: história e historiografia. São Paulo: HUCITEC / Fapesp, 2005.

NOVAIS, Fernando. Portugal e Brasil na crise do antigo sistema colonial (17771808). São Paulo: Editoria Hucitec, 1979.

PERROTA, Cosimo. La disputa sobre los pobres en los siglos XVI y XVII: España entre desarollo y regresión. In Cuadernos de CC. EE, n.o 37, 2000.

PIMENTA, João Paulo Garrido. De Raynal a De Pradt: apontamentos para um estudo da ideia de emancipação da América e sua leitura no Brasil. In Almanack Braziliense. São Paulo, n¹1: 88-99, maio. 2010.

POCOCK, John Greville Agard. Linguagens do ideário político. São Paulo: EDUSP, 2003: 83-99.

ROOVER, Raymond. The concept of the just price: theory and economic policy. In The Journal of Economic History, Vol. 18, No. 4, (Dec., 1958).

SCHUMPETER, Joseph Alois. The Scholastic Doctors and the Philosophers of Natural Law. In History of Economic Analysis. New York: Oxford University Press, 2003.

SILVA, José Carneiro da. Memória topográfica e histórica sobre os Campos dos Goitacazes. Rio de Janeiro: Leuzinger, 1907 (1a edição de 1819).

SILVA, Lucio Craveiro da. Luis de Molina. In CALFATE, Pedro (dir.). História do pensamento filosófico Português. Lisboa: Editorial Caminho, 2001, $2^{\circ}$ Volume (Renascimento e Contra-Reforma). 
SIQUEIRA, Sônia. A escravidão negra no pensamento do Bispo Azeredo Coutinho: contribuição ao estudo da mentalidade do último inquisidor geral. In Revista de História. São Paulo: 14(27).

SUBRAHMANYAM, Sanjay. Comércio e conflito: a presença portuguesa no Golfo de Bengala (1500-1700). Lisboa: Edições 70, 1994.

O Império Asiático Português: uma história política e econômica (1500-1700). Lisboa: Difel, 1995.

TRIBE, Keith. Cameralism and the science of government. In Strategies of economic order: German economic discourse (1750-1950). NewYork: Cambridge University Press, 2007.

TUCK, Richard. Natural Rights Theories: their origin and development. Cambridge and New York: Cambridge University Press, 1979. 
